\title{
New In-Depth Analytical Approach of the Porcine Seminal Plasma Proteome Reveals Potential Fertility Biomarkers
}

Cristina Perez-Fatino, Inmaculada Parrilla, Isabel Barranco, Maria VergaraBarberan, Ernesto F. Simo-Alfonso, J ose M. Herrero-Martinez, Heriberto RodriguezMartinez, Emilio A. Martinez and J ordi Roca

The self-archived postprint version of this journal article is available at Linköping University Institutional Repository (DiVA):

http:/ / urn.kb.se/ resolve?urn=urn:nbn:se:liu:diva- 147142

N.B.: When citing this work, cite the original publication.

Perez-Fatino, C., Parrilla, I., Barranco, I., Vergara-Barberan, M., Simo-Alfonso, E. F., HerreroMartinez, J . M., Rodriguez-Martinez, H., Martinez, E. A., Roca, J ., (2018), New In-Depth Analytical Approach of the Porcine Seminal Plasma Proteome Reveals Potential Fertility Biomarkers, J ournal of Proteome Research, 17(3), 1065-1076. https:// doi.org/ 10.1021/ acs.jproteome.7b00728

Original publication available at:

https:// doi.org/ 10.1021/acs.jproteome.7b00728

Copyright: American Chemical Society

http:/ / pubs.acs.org/ 
This document is confidential and is proprietary to the American Chemical Society and its authors. Do not copy or disclose without written permission. If you have received this item in error, notify the sender and delete all copies.

\title{
A new in-depth analytical approach of the porcine seminal plasma proteome reveals potential fertility biomarkers
}

\author{
Journal: Journal of Proteome Research \\ Manuscript ID pr-2017-00728j.R1 \\ Manuscript Type: Article \\ Complete List of Authors: $\quad$ Pérez-Patiño, Cristina; Univ Murcia, Medicine and Animal Surgery \\ Parrilla, Inmaculada; Univ Murcia, Medicine and Animal Surgery \\ Barranco, I sabel; Univ Murcia, Medicine and Animal Surgery \\ Vergara-Barberán, María; University of Valencia, Analytical Chemistry \\ Simo-Alfonso, Ernesto; University of Valencia, Analytical Chemistry \\ Herrero-Martínez, J ose; University of Valencia, Analytical Chemistry \\ Rodríguez-Martínez, Heriberto; Linköping University, Department of Clinical \\ \& Experimental Medicine (IKE) \\ Martinez, Emilio; Univ Murcia, Medicine and Animal Surgery \\ Roca, Jordi; Univ Murcia, Medicine and Animal Surgery
}

Date Submitted by the Author: 16-Jan-2018 


\title{
A new in-depth analytical approach of the porcine seminal plasma proteome reveals potential fertility biomarkers
}

\author{
Cristina Pérez-Patiño ${ }^{1}$ Inmaculada Parrilla ${ }^{1}$, Isabel Barranco ${ }^{1}$, María Vergara- \\ Barberán ${ }^{2}$, Ernesto F. Simó-Alfonso ${ }^{2}$, José M. Herrero-Martínez ${ }^{2}$, Heriberto Rodriguez- \\ Martínez ${ }^{3}$, Emilio A. Martínez ${ }^{1}$ Jordi Roca ${ }^{1}$. \\ ${ }^{1}$ Department of Medicine and Animal Surgery, Faculty of Veterinary Science, \\ University of Murcia, Spain; ${ }^{2}$ Department of Analytical Chemistry, University of \\ Valencia, Spain; and ${ }^{3}$ Department of Clinical \& Experimental Medicine (IKE), \\ Linköping University, Sweden \\ * Corresponding author: Jordi Roca (roca@um.es)
}

Keywords: seminal plasma, proteome, fertility, pig.

\begin{abstract}
A complete characterization of the proteome of seminal plasma (SP) is an essential step to understand how SP influences sperm function and fertility after artificial insemination (AI). The purpose of this study was to identify which among characterized proteins in boar-SP were differently expressed among AI-boars with significantly different fertility outcomes. A total of 872 SP-proteins, 390 of them belonging specifically to Sus Scrofa taxonomy, were identified (Experiment 1) by using a novel proteomic approach that combined size exclusion chromatography and solid phase extraction as pre-fractionation steps prior to Nano LC-ESI-MS/MS analysis. The SP-


proteomes of 26 boars showing significant differences in farrowing rate $(n=13)$ and litter size $(\mathrm{n}=13)$ after the AI of 10,526 sows were further analyzed (Experiment 2). A total of 679 SP-proteins were then quantified by the SWATH approach where the penalized linear regression LASSO revealed differentially expressed SP-proteins for farrowing rate (FURIN, AKR1B1, UBA1, PIN1, SPAM1, BLMH, SMPDL3A, KRT17, KRT10, TTC23 and AGT) and litter size (PN-1, THBS1, DSC1 and CAT). This study extended our knowledge of the SP-proteome and revealed some SP-proteins as potential biomarkers of fertility in AI-boars.

\section{Introduction}

Artificial insemination (AI) is worldwide used by the porcine industry as it is considered the best breeding tool to disseminate genetic progress and, in consequence, to efficiently improve the production of high-quality pork meat. ${ }^{1}$ Currently, large numbers of semen AI-doses, usually at liquid state, are daily produced by specialized AI-centers following rigorous sanitary and semen quality controls. Despite this, fertility drops are routinely recorded among swine farms and attributed to males; most often linked to individual boars than to breeds or genetic lines. ${ }^{2}$ Between 5 to $7 \%$ of boars in AI-centers showing normal ejaculates and thereby used to produce semen AI-doses are sub-fertile, leading to serious productive and economic losses to farmers. ${ }^{2}$ This reality highlights current semen assessments performed by AI-centers are unfortunately unable to identify sub-fertile boars, despite being carried out using innovative technologies such as computer assisted sperm analysis (CASA) or flow-cytometry-based procedures. ${ }^{3}$ Consequently, pig AI-centers are calling for new semen evaluation tests capable to early identify sub-fertile boars, ideally before their semen is incorporated into 
commercial AI-programs. ${ }^{4}$ An area of relevant analysis is the seminal plasma (SP), since it is the fluid accompanying the spermatozoa. Analyses of the SP-composition might explain the evident individual variability in fertility among selected AI-boars.

Boar SP consists of a mixture of secretions from the testis, epididymis and, mainly, from the male accessory sexual glands which thus yields a complex composition, ${ }^{5}$ with potential relevance for sperm functionality and even fertility. ${ }^{6,7}$ Recent findings in pigs support this relevance, with the findings that some SP-proteins could contribute to fertility outcomes of liquid stored boar semen AI-doses by either promoting it, as Glutathione Peroxidase 5, Paraoxonase-I, Osteopontin or Heat Shock Protein $70^{8-11}$ or hindering it, as PSP-I and AQN-3. ${ }^{8}$ These findings, albeit preliminary in nature as they were focused exclusively on specific proteins, strongly indicate that SP-proteins are involved in regulating sperm fertility in boars. Moreover, the above results also highlighted that an extensive knowledge of SP-proteome is a prerequisite in the search of SP-proteins with prediction value for fertility of AI-boars, at the earliest possible stage. Recently, some large-scale studies have been performed to decode the boar SPproteome and more than 500 proteins have been identified. ${ }^{12-14}$ Although worthy, this number of proteins is far below the identified numbers in i.e. human SP, with more than 2,000 SP-proteins described, ${ }^{15-18}$ thus calling for further research to completely decode the boar SP-proteome. Thus, the present study firstly aimed to increase our knowledge of the boar SP-proteome, to later look for qualitative and/or quantitative differences between fertile and subfertile boars. To achieve the first aim, the effectiveness of a fractionation approach based on novel solid-phase extraction (SPE) sorbent instead of the traditional used size exclusion chromatography (SEC) was tested (Experiment 1). This sorbent has been successfully applied for selective retention of some highabundant proteins, such as bovine serum albumin, ${ }^{19}$ as well as for the isolation/pre- 
concentration of low-abundant proteins in complex matrices, e.g. lectins and viscotoxins in mistletoe extracts. ${ }^{19,20}$ This scenario of highly-abundant proteins masking lowabundant ones is a recurring trouble when aiming the complete decoding of the proteome of biological fluids containing complex mixtures of proteins, such as the SP. ${ }^{14}$ Once the new spectral library was generated, the second objective was addressed (Experiment 2), disclosing the SP-proteome profile of AI-boars ( $\mathrm{n}=64)$ with significant differences in fertility, measured in terms of farrowing rate (FR) and litter size (LS) of a very large number of inseminated females $(>20,000)$. This profiling focused on the quantification of relative 'label free' proteins using the SWATH approach.

\section{Material and methods}

2.1 Animals and fertility records

All procedures involving animals were performed according to international guidelines (Directive 2010/63/EU), following the approval of the Bioethics Committee of Murcia University (research code: 639/2012).

An initial population of 64 healthy and sexually mature boars of Landrace, Large White or the Pietrain breed delivered semen for the study. Preliminary fertility records of these boars suggested that they could show deviation in fertility outcomes from the average boar population within each breed. All boars belonged to the Topigs Norsvin España (Madrid, Spain) and were housed in four AI-centers located in Murcia, Soria, Lérida and León (Spain). The boars had high genetic merit and were included in AI-programs for genetic improvement. The boars were subjected to the same management conditions, specifically housed in individual pens in buildings with controlled light-regime (16 h per day) and temperature $\left(15-25^{\circ} \mathrm{C}\right)$ and with free access to water. The boars were fed 
with commercial feedstuff according to the nutritional requirements for adult boars subjected to regular ejaculate collection.

The inseminated sows, a total of 25,069 animals, were multiparous (1-7 farrowings) belonging to Large White, Landrace or Pietrain breed, and housed in different commercial farms located in Spain. The sows were cervically inseminated twice using 24-72 h liquid-stored semen AI-doses (2,500 x $10^{6}$ sperm extended to $80 \mathrm{~mL}$ of a commercial extender). Semen AI-doses were prepared from entire ejaculates that fulfilled the standard of quantity and sperm quality thresholds, specifically $>200 \times 10^{6}$ sperm/mL, $75 \%$ of them motile and $85 \%$ depicting normal morphology. Fertility data was recorded over a 12-month period in terms of FR (number of farrowing sows respect to the number of inseminated sows) and LS (total number of piglets born per litter).

\subsection{Seminal plasma sampling and storage}

A total of 256 entire ejaculates were collected in a single container, using a semiautomatic collection procedure, during the 12 months that the boars were used in the AI-program. Immediately after ejaculate collection, two fully filled 15-mL tubes from each ejaculate were centrifuged twice at 1,500 $\mathrm{xg}$ at rt for $10 \mathrm{~min}$ (Rotofix 32A; Hettich Zentrifugen, Tuttlingen, Germany). The second supernatant was microscopically examined to ensure that it was sperm-free and thereafter split in 2-mL cryotubes, stored at $-20^{\circ} \mathrm{C}$. The cryostored SP-samples were shipped in insulated containers with dry ice $\left(-79^{\circ} \mathrm{C}\right)$ to the Andrology Laboratory of the University of Murcia (Spain), where they were stored at $-80^{\circ} \mathrm{C}$ (Ultra Low Freezer; Hier, Schomberg, Ontorio, Canada) until proteome analysis.

\subsection{Proteome analysis}

\subsubsection{Preparation of seminal plasma samples}


The proteome analyses were carried out in the Proteomics Unit of the University of Valencia, Valencia, Spain (member of the PRB2-ISCIII ProteoRed Proteomics Platform). The SP-samples were thawed at rt and a protease inhibitor cocktail (SigmaAldrich, St. Louis, MO, USA) was added (1\%, vol/vol), before centrifugation to 16,100 $x g$ at $4^{\circ} \mathrm{C}$ for $1 \mathrm{~min}$. Total protein concentration was measured using a Qubit fluorometer (Invitrogen, Carlsbad, CA, USA) following the manufacturer instructions. Aliquots of each of all SP-samples (64 SP-samples from 16 boars, 4 samples per boar) were mixed in a single pool for full characterization of the proteome (Experiment 1). Similarly, SP-samples (from 4 ejaculates) of 26 boars were used to identify and quantify differentially expressed proteins between boars showing highest and lowest fertility records (Experiment 2).

Two pre-fractionation approaches, SEC and SPE, were used to reduce the complexity of protein composition of the SP-samples. The SEC approach was carried out in an ETTAN LC system (GE Healthcare Life Science, Little Chalfont, United Kingdom) using a Superdex 200 5/150 GL column (GE Healthcare Life Science) following our previously described protocol. ${ }^{14}$ Briefly, $50 \mu \mathrm{L}$ of the pooled SP-sample (75 $\mu \mathrm{g}$ of protein) were injected into the column at a flow rate of $0.18 \mathrm{~mL} / \mathrm{min}$ at $4^{\circ} \mathrm{C}$. The eluent was collected into different $0.2 \mathrm{~mL}$-fractions which were dried in a rotatory evaporator and loaded in a 12\% Tris-HCl precast 1-D SDS PAGE (Bio-Rad, Richmond, CA, USA). After this run, the gel was sliced at $38 \mathrm{kDa}$ and the top of the gel was used in order to analyze the masked proteins by in gel-digestion processing. Secondly, a SPE with glycidyl methacrylate (GMA)-based polymer modified with cysteamine and treated with gold nanoparticles (AuNPs) was carried out to retain and separate proteins according to their pI value as described recently by Vergara-Barberán et al. ${ }^{20}$ Briefly, a GMA-co-ethylene dimethacrylate (EDMA) polymer was prepared by mixing GMA (20 
wt\%; Sigma-Aldrich), EDMA (5 wt\%; Sigma-Aldrich), cyclohexanol (70 wt\%), 1dodecanol (5 wt\%) and azobisisobutyronitrile (1 wt\%; Fluka, Buchs, Switzerland) followed by thermal polymerization at $60^{\circ} \mathrm{C}$ for $24 \mathrm{~h}$. The resulting material was grounded and sieved (with pore size $\leq 100 \mu \mathrm{m}$ ), treated with an aqueous solution of cysteamine $2.5 \mathrm{M}$ during $2 \mathrm{~h}$, and then washed with deionized water until reaching a neutral pH. Finally, $400 \mathrm{mg}$ of thiol-modified GMA were saturated with $100 \mathrm{~mL}$ of AuNPs metallic suspension (Alfa Aesar, Landcashire, United Kingdom). To perform the SPE approach, the cartridges were prepared as described by Vergara-Barberán et al., ${ }^{20}$ placing $50 \mathrm{mg}$ of the modified polymer onto 1-mL propylene SPE cartridge (Análisis Vínicos, Tomelloso, Spain) using two frits (1/16’, $20 \mu \mathrm{m})$. The SPE sorbents were activated with $200 \mu \mathrm{L}$ of acetonitrile (ACN; Scharlab, Barcelona, Spain) and equilibrated with $500 \mu \mathrm{L}$ of deionized water. Then, $200 \mu \mathrm{L}$ of the SP-pool sample in 25 $\mathrm{mM}$ phosphate buffer solution (PBS) adjusted at either $\mathrm{pH} 8.2$ or $\mathrm{pH} 9$, were passed through the SPE material at a flow rate of $0.1 \mathrm{~mL} / \mathrm{min}$. The washing step was carried out with PBS (under the same $\mathrm{pH}$ conditions as the loading step) at $0.7 \mathrm{~mL} / \mathrm{min}$. Finally, the elution of the retained proteins was carried out using $200 \mu \mathrm{L}$ of $25 \mathrm{mM}$ PBS (pH 12) at $0.1 \mathrm{~mL} / \mathrm{min}$. A total of $75 \mu \mathrm{g}$ of protein from all steps fractions (loading, washing and elution fractions) was collected (Table S1). Each collected fraction was loaded onto different wells of $12 \%$ Tris-HCl precast 1-D SDS PAGE (Bio-Rad). The gel was run at a constant voltage of $200 \mathrm{mV}$ for $30 \mathrm{~min}$ at room temperature including a molecular weight marker (ECL Plex Fluorescent Rainbow Marker, GE Healthcare Life Sciences). Coomassie Brilliant R250 Blue stain (Bio-Rad) was used to visualize protein bands on the gel. The eluted gel band was sliced in 10 fragments and used to analyze masked proteins by in-gel digestion processing.

\subsubsection{Building a MS/MS library for SWATH analysis of boar SP}




\subsubsection{Complete proteome: In-solution digestion processing}

The complete proteome (Experiment 1) was analyzed from an aliquot of the mixed SPsample treated by in-solution processing following the steps described previously by Perez-Patiño et al. $^{14}$ Briefly, three $\mu \mathrm{L}$ of the pooled SP for proteome analysis, containing $10 \mu \mathrm{g}$ of proteins, were digested with Sequencing Grade Trypsin (Promega Corporation, Madison, USA) to generate peptides of each individual protein. The final concentration of protein in the digested sample was $0.13 \mu \mathrm{g} / \mu \mathrm{L}$.

\subsubsection{Low-abundant proteins: In-gel digestion processing}

The portion of the 1-D SDS PAGE from SEC containing proteins with a molecular weight higher than $38 \mathrm{kDa}$ and the portion of the 1-D SDS PAGE from SPE containing proteins from the eluted fraction were processed by in-gel digestion processing. After washing with deionized water, the gel was dehydrated in ACN, reduced with dithiothreitol (DTT) and alkylated with iodoacetamide (IAM). The slide was cut into 10 small pieces of approximately $1 \mathrm{~mm}^{2}$ in size and then transferred into 1.5-mL Eppendorf tubes. Sequencing Grade Trypsin digestion of the sliced gel was performed following the protocol used by Shevchenko et al. ${ }^{21}$

\subsubsection{LC-MS/MS analysis}

The peptides recovered from in-gel and in-solution digestion processing were examined by LC using a NanoLC Ultra 1-D plus Eksigent (Eksigent Technologies, Dublin, CA, USA) which was directly connected to an AB SCIEX TripleTOF 5600 mass spectrometer (AB SCIEX, Framingham, MA, USA) in direct injection mode. Briefly, 5 $\mu \mathrm{L}$ from each digested sample were trapped on a NanoLC pre-column (3 $\mu$ m particles size C18-CL, $350 \mu \mathrm{m}$ diameter x 0.5 mm long; Eksigent Technologies) and desalted with $0.1 \%$ trifluoroacetic acid (TFA) at $3 \mu \mathrm{L} / \mathrm{min}$ during $5 \mathrm{~min}$. Then, the digested 
peptides present in the samples were separated using an analytical LC-column (3 $\mu \mathrm{m}$ particles size C18-CL, $75 \mu \mathrm{m}$ diameter x 12 cm long, Nikkyo Technos Co®, Tokyo, Japan) equilibrated in 5\% ACN $0.1 \%$ formic acid (FA; Fisher Scientific). Peptide elution was performed by applying a mixture of solvents A and B; solvent A was $0.1 \%$ FA in water and solvent B was $0.1 \%$ FA in ACN. The peptides were eluted from the column with a linear gradient from $5 \%$ to $35 \%$ of solvent $\mathrm{B}$ at a constant flow rate of $300 \mathrm{~nL} / \mathrm{min}$ over $90 \mathrm{~min}$.

The eluted peptides were thereafter direction-ionized using an ESI Nanospray III (AB SCIEX) and then analyzed on an AB SCIEX TripleTOF 5600 mass spectrometer coupled to the NanoLC system. The samples were ionized applying $2.8 \mathrm{kV}$ to the spray emitter and the TripleTOF was operated in data-dependent mode, in which a TOF MS scan was made from 350 to 1,259 m/z, accumulated for $250 \mathrm{~ms}$ TOF followed by 150 ms TOF with the same scan rage for MS, and the 25 most abundant multiply charged $(2+, 3+, 4+$ or $5+)$ precursor peptide ions automatically selected. Ions with $1+$ and unassigned charge states were rejected from the MS/MS analysis.

\subsubsection{LC-SWATH-MS acquisition}

To determine quantitative differences in SP-protein composition among boars (Experiment 2), the SWATH analysis of individual SP-pool samples followed the same procedure previously described by Perez-Patiño et al. ${ }^{14}$ tuning the TripleTOF 5600 (AB SCIEX) as described by Gillet et al. ${ }^{22}$ for SWATH-MS-based experiments. Briefly, the mass spectrometer was operated in a looped product ion mode where the instrument was specifically tuned to allow a quadrupole resolution of $\mathrm{Da} /$ mass selection. The stability of the mass selection was kept by the operation of the Radio Frequency (RF) and Direct Current (DC) voltages on the isolation quadrupole in an independent manner. A set of 
37 overlapping windows, covering the mass range 450-1000 Da, was constructed using an isolation width of $16 \mathrm{Da}$ (15 Da of optimal ion transmission efficiency and $1 \mathrm{Da}$ for the window overlap). Consecutive swaths need to be acquired with some precursor isolation window overlap to ensure the transfer of the complete isotopic pattern of any given precursor ion in at least one isolation window and, thereby, to maintain optimal correlation between parent and fragment isotopes peaks at any LC time point. In this way, $5 \mu \mathrm{L}$ of each single pool was loaded onto a trap column (NanoLC Column, $3 \mu \mathrm{m}$ C18-CL, $75 \mu \mathrm{m} \times 15 \mathrm{~cm}$; Eksigent Technologies) and desalted with 0.1\% TFA at $3 \mu \mathrm{L} / \mathrm{min}$ during $5 \mathrm{~min}$. The peptides were loaded onto an analytical column (LC Column, $3 \mu \mathrm{m}$ C18-CL, $75 \mu \mathrm{m}$ x 12 cm, Nikkyo Technos Co®) equilibrated in 5\% ACN $0.1 \%$ FA. Peptide elution was carried out with a linear gradient of 5 to $40 \%$ B in $90 \min (\mathrm{A}: 0.1 \% \mathrm{FA}$; B: ACN, 0.1\% FA) at a flow rate of $300 \mathrm{~nL} / \mathrm{min}$. Eluted peptides were infused in the spectrometer nanoESI qQTOF (SCIEX TripleTOF 5600). The TripleTOF was operated in SWATH mode, in which a 0.050 s TOF MS scan from 350 to $1250 \mathrm{~m} / \mathrm{z}$ was performed, followed by $0.080 \mathrm{~s}$ product ion scans from 230 to 1800 $\mathrm{m} / \mathrm{z}$ on the 37 defined windows (3.05 sec/cycle). Collision energy was set to optimum energy for a 2+ ion at the center of each SWATH block with a $15 \mathrm{eV}$ collision energy spread. The mass spectrometer was always operated in high sensitivity mode.

2.4 Data processing: protein identification, validation and quantification

After LC-MS/MS, The SCIEX.wiff data-files were processed using ProteinPilot v5.0 search engine (AB SCIEX). The Paragon algorithm (4.0.0.0, 4767) of ProteinPilot was used to search against the National Center for Biotechnology Information nonredundant protein sequence database (NCBInr; 70353186 proteins searched) with the following parameters: trypsin specificity, cys-alkylation (IAM), no taxonomy restricted, and the search effort set to through. To avoid using the same spectral evidence in more 
than one protein, the identified proteins were grouped based on MS/MS spectra by the Protein-Pilot Pro Group ${ }^{\mathrm{TM}}$ Algorithm, regardless of the peptide sequence assigned. The protein within each group that could explain more spectral data with confidence was depicted as the primary protein of the group. The resulting Protein-Pilot group file was loaded into PeakView ${ }^{\circledR}$ (v2.1, AB SCIEX) and peaks from SWATH runs were extracted with a peptide confidence threshold of $97 \%$ confidence and a false discovery rate (FDR) less than 1\%. The peptide confidence threshold was not set for a minimum number of peptides quantified but 6 transitions per peptide were necessary for quantify one peptide. The extracted ions chromatograms were integrated and the areas used to calculate total protein. A normalization of the calculated areas was done by total sum and the sum of all areas was equalized for all the samples.

2.5 Gene ontology and bioinformatics analysis

The bioinformatics of identified and validated SP-proteins was manually performed using the comprehensive bioinformatics tool for functional annotation UniProt KB database (www.uniprot.org) downloaded 15/05/2017, containing 553,941 reviewed entries of them 1,419 in Sus Scrofa taxonomy. This analysis allowed elucidation of the different functions and processes in which the identified and validated proteins would be putatively involved. Three independent sets of ontology were used in the annotation: "the molecular function”, "the biological processes", with a special mention to the reproductive process, and their "cellular component". Proteins without similarity to database entries were not considered for collation.

2.6 Statistical analysis

Data were statistically analyzed using IBM SPSS (v19.0, IBM Spain, Madrid) and R software (R Foundation Members Supporters. www.r-project.org/, June 2014). Fertility 
data of each boar were recorded as direct boar effect (DBE). To do this, the raw fertility dataset was corrected for parameters related to farm and sow by using the multivariate statistical model previously described by Broekhuijse et al. ${ }^{23}$ The quantitative data obtained by PeakView ${ }^{\circledR}$ were analyzed using MarkerView ${ }^{\circledR}$ (v1.2, AB SCIEX). Firstly, peak areas were normalized by the sum of peak areas of all identified peptides and then, a penalized linear regression model using LASSO (least absolute shrinkage and selection operator) ${ }^{24}$ was used to identify quantitative differently expressed SP-proteins among boars exhibiting different reproductive outcomes, specifically in FR and LS. Two different shrinkage factors $(\lambda)$ were used for running the LASSO regression analyses, specifically $\lambda_{1}$ and $\lambda_{2}$, which were the median value obtained after replicating 100 times the cross validation and the minimum value obtained for the model, respectively. The explanatory ability of resulting selected proteins was showed using heatmaps after z-score normalization.

\section{Results}

\subsection{Fertility records}

The initial fertility data set included 64 boars with a total of 25,069 inseminated sows (Table S2). Of the 64 boars, those showing largest FR and LS deviations regarding to average values of its genetic line averaged were finally selected, totaling 26 boars with 10,526 inseminated sows (Figure 1). Table 1 shows the fertility outcomes of the 26 boars, including the number of sows inseminated per boar. Thirteen boars were selected for showing highest deviations in FR and other 13 for showing largest deviation in LS (Figure 2) with 5,449 and 5,077 inseminated sows, respectively. The selected boars showed deviations from genetic line average by at least 1.5\% in FR or 0.3 litters in LS. 
3.2 Characterization of the boar seminal plasma proteome

In Experiment 1, a single pooled SP sample from 64 ejaculates of 16 boars (4 ejaculates per boar) was analyzed. The use of SEC as pre-fractionation step allowed identifying a total of 35,093 spectra corresponding to 8,118 distinct peptides and 524 SP-proteins with a FDR $\leq 1 \%$ at protein level (Table S3). The use of SPE as pre-fractionation step allowed to increase the number of spectra identified to 94,585 , corresponding to 9,849 distinct peptides and 810 SP-proteins with a FDR $\leq 1 \%$ at protein level (Table S4). These 810 SP-proteins resulted of the sum of SP-proteins identified in the two SPE performed at different pHs. At pH 8.4618 SP-proteins were identified, whereas at $\mathrm{pH}$ 9.2 678 SP-proteins were identified. In sum, the combination of the two prefractionations steps (SEC and SPE), revealed a total of 134,605 spectra corresponding to 13,975 distinct peptides and 872 SP-proteins identified with a FDR $\leq 1 \%$ at protein level. The complete list of the 872 SP-proteins identified, including their Unused Score, UniProt Accession number, Protein Name, Species, \% of Sequence Coverage and Matched Peptides is provided in Table S5. A total of 390 SP-proteins was characterized as belonging to Sus Scrofa taxonomy. The SWATH approach allowed the quantification of 679 SP-proteins present in all the SP-samples analyzed (Table S6).

\subsection{Bioinformatics Analysis}

A total of 842 of the 872 SP-proteins identified were successfully mapped to UniProt KB for protein enrichment. The results are shown in Figure 3. A total of 854 hits where framed into molecular function (Figure 3a), showing many of them catalytic (349, 41\%) and binding (239, 28\%) activities. Some others appeared showing regulatory (89, 10\%) and structural molecule $(83,10 \%)$ activities. Only 13 (2\%) of them showed antioxidant activity. A total of 1,730 hits were enclosed into biological process (Figure 3b) and 
more than half of them were included into four fundamental biological issues: cellular (317, 18\%), single-organism (312, 18\%), biological regulation $(256,15 \%)$ and metabolic (246, 14\%) processes. Noticeably, a total of 44 (2\%) hits corresponding to 37 SP-proteins were classified as specifically implicated in reproductive processes (Figure 3d). In particular, fourteen of these 37 SP-proteins (32\%) were involved in fertilization process, 8 (18\%) in modulating spermatogenesis and sperm capacitation and 5 (11\%) in placental development. The rest of SP-proteins implicated in reproductive process were involved in reproductive structure development $(6,14 \%)$, male accessory sexual gland development (4, 9\%), oocyte and ovarian follicle development (3, 7\%), oestrus cycle regulation and oogenesis (2, 5\%) and finally, embryo implantation (2, 4\%). At the end, a total of 1,359 hits were enriched for cellular components (Figure 3c). Most of them belonged to the cell part group (421, 31\%), predominantly in cell organelles (190, 14\%) and membranes (167, 12\%). A total of 366 (27\%) SP-proteins belonged specifically to the extracellular region.

3.4 Differences in SP-proteome profile among boars with different fertility

In Experiment 2, 26 SP samples (each one constituted as a pool of 4 ejaculates from each single boar) from 26 boars of different breeds were separately analyzed. The LASSO penalized regression analyses were used to identify quantitative differentially expressed SP-proteins among boar populations with significant differences in fertility outcomes. For FR, 11 SP-proteins were quantitative differentially expressed between high- and low-FR boars using the penalty parameter $\lambda_{2}$, as illustrated in the heatmap of Figure 4. Relative amount of these 11 differentially expressed SP-proteins in each boar is showed in Table S7. Eight and three of these 11 SP-proteins were over- respectively under-expressed in boars showing high-FR (Table 2). To LS, the LASSO analysis using $\lambda_{1}$ identified four SP-proteins quantitative differentially expressed between boars 
showing large- and small-LS, as illustrated in the heatmap of Figure 5. Two of these SPproteins were over-expressed and the other two under-expressed in boars showing largeLS (Table 3). The relative amounts of these four differentially expressed SP-proteins in each boar are given in Table S8.

\section{Discussion}

To the best of our knowledge, this would be the first large-scale SP-proteome study carried out in a livestock polytocous species highlighting a quantitative profile of differentially expressed SP-proteins among AI-sires showing differences in fertility outcome. Moreover, the findings revealed the presence of SP-proteins that would be specifically related to either FR or LS, indicating their value for the earliest possible prognosis of fertility and prolificacy by targeted analyses of the SP. This work should be considered as a first step that should be continued with others focused on evaluating the specific relevance to fertility of each of the SP-proteins disclosed herein.

The presence of sub-fertile sires in AI-centers is a serious problem for the livestock industry because it compromises the reproductive performance of production farms and, thereby, the economic profit of farmers. In swine, where currently a single AI-boar can yearly produce semen AI-doses for inseminating more than 5,000 sows, ${ }^{4}$ a single AIboar producing 0.5 piglet less per litter than expected could cause economic losses above 30,000 euros/year. ${ }^{2}$ Therefore, AI-boars showing downward deviation of 0.5 piglets per litter or $2-3 \%$ in farrowing rates are considered sub-fertile. ${ }^{2}$ Currently, it is 
estimated that between 5 to $7 \%$ of boars housed in AI-centers could be considered as sub-fertile. $^{2}$ The present study has found some AI-boars that fulfill the above requirements for sub-fertility thus accurately reflecting the situation in the field, and proving the selected animals are a properly selected cohort sample.

To identify the largest possible number of SP-proteins related to fertility outcomes, the first challenge of the present study was to try to enhance the number of existing boar SP-proteins identified. To date, the most complete proteome of boar SP gathered a total of 536 proteins, ${ }^{14}$ which is below what was found in other species. Those results highlighted that many low-abundant SP-proteins cannot be identified because they were masked by high-abundant SP-proteins, a recurrent problem in complex biological fluids as $\mathrm{SP}^{15,25}$ and clearly visible in pigs, ${ }^{14}$ where the analytical method used was a limiting factor for full identification of boar SP-proteins. To solve this methodological trouble, a protein pre-fractionation step based on SPE using sorbents with proper selectivity was used instead of the traditional SEC. The SPE allowed to remove the high-abundant SPproteins and, consequently, to reveal the low-abundant ones. The SPE support is based on a polymeric solvent modified with cysteamine as ligand for a posterior assembly of AuNPs. ${ }^{20}$ The polymer provides a porous structure that leads to a low-back pressure thus improving the extraction efficiency, allowing larger flow rates and shortening the operation time. ${ }^{26}$ Besides, the incorporation of AuNPs to these materials constitutes a promising way of increasing the surface areas as well as to serve as new platforms for further tailoring its selective properties. ${ }^{27,28}$ In the present study, SPE was carried out at two different pHs, following the recommendation of Vergara-Barberán et al. ${ }^{19,20}$ that demonstrated a key role for $\mathrm{pH}$ to efficiently retain proteins onto the surface of AuNPs. The performed SPE allowed the recovery of a total of 13,975 peptides characterizing a total of 810 proteins. The combination of the two spectral libraries generated by using 
SEC and SPE resulted in a SP-proteome of 872 proteins, 336 more than the earlier largest SP-proteome known. ${ }^{14}$ Other previous studies focused on the description of the porcine SP-proteome ${ }^{12,13}$ have identified only four SP-proteins which were not identified in the present study, specifically the serine protease inhibitor Kazal-type 13like, seminal vesicles $14 \mathrm{kDa}$ protein, ras-related protein Rab-22A and CUE domaincontaining protein-1 like. These differences could be attributed to the search engine used in the present study. In fact, the two above quoted papers used MASCOT, whereas in the present study the Paragon algorithm of ProteinPilot was selected. ${ }^{29,30}$

Thirty-seven of the 872 SP-proteins recorded in the present boar SP-samples were assorted in databases as involved in reproductive functions, highlighting the highly abundant low-molecular weight glycoproteins spermadhesins. ${ }^{31}$ The spermadhesins identified in the current SP-samples were the five previously identified as characteristics of boar SP, namely PSP-I, PSP-II, AWN, AQN-1 and AQN-3, which could represent more than $90 \%$ of the total protein load in boar SP. ${ }^{31,32}$ Spermadhesins play relevant roles in sperm capacitation, sperm-oocyte interaction and in modulating the uterine immune environment for a later successful embryo development. ${ }^{33}$ None of these spermadhesins were quantitative differentially expressed between SP-samples of boars showing differences in fertility in the present study. The relationship between some of these SP-spermadhesins and boar fertility has been previously evaluated and the PSP-I was the only one showing a negative relation with fertility records (LS). ${ }^{8}$ These authors also noted that the concentration of PSP-I was higher in the SP from the sperm-poor ejaculate fraction than in the sperm-rich fraction, which is consistent with previous studies demonstrating that the sperm-poor ejaculate fraction, not only contains the largest SP volume in boar ejaculate, but also the highest amount of proteins per mL. ${ }^{14,34}$ In addition, spermadhesins are considered carrier proteins with a wide range of ligand- 
binding abilities, ${ }^{35}$ leading they are over-expressed in SP, minimizing putative differential expression between SP-samples, particularly in those from entire ejaculates. These facts could explain the apparent discrepancy between our results and those reported by Novak and coworkers. ${ }^{8}$ They used only the sperm-rich fraction to prepare the AI-doses while we used the entire ejaculate (both ejaculate fractions collected in a single container) for both analyses and preparation the AI-doses used to render information on fertility. A tempting possibility is that differences in fertility may arise from differences in the relative volume of the post-SRF (the sperm poorest fraction) among boars, a matter that has -to the best of our knowledge- not been carefully studied/documented. In relation to this question, it is important to mention that insemination centers are currently moving, for hygiene and labour reasons, from collecting only the sperm-rich ejaculate fraction to collect the entire ejaculate, ${ }^{4}$ as performed in the present study, thus requiring further studies on SP-relative volume and fertility. Only one of these 37 SP-proteins classified with reproductive function in databases was quantitatively differentially expressed among the SP-samples of high and less fertile boars. Specifically, the hyaluronidase sperm adhesion molecule 1 (SPAM1), whose significance will be discussed later.

The data set of quantified SP-proteins was statistically analyzed using LASSO approaches for a consistent identification of the SP-proteins more related to boar fertility traits. The LASSO approaches allow both to select highly explanatory variables, in our case for differences in fertility traits, and to discard those variables that are not very significant. ${ }^{36}$ The final number of variables selected in LASSO approaches depends of the level of shrinkage, defined by factor $\lambda$. The factors $\lambda$ used in the present study were particularly restrictive, leading to the selection of a small number of SPproteins, albeit with high explanatory power. The fertility traits evaluated were FR and 
LS, where their relationship with SP-proteins was independently evaluated. The LASSO approaches identified 11 SP-proteins quantitatively differentially expressed between boars with high- or low-FR. Eight of the proteins were over-expressed and the other three under-expressed in the boars showing high-FR. Four of the eight SP-proteins overexpressed in boars showing high-FR, specifically Keratin I type cytoskeletal 17 (KRT17), a Peptidyl-prolyl cis-trans isomerase (PIN1), Sphingomyelin phosphodiesterase acid like 3A (SMPDL3A) and Bleomycin Hydrolase (BLMH), were so far not directly related to reproductive function in either male or female mammals. Keratin proteins protect epithelial cells against mechanical and non-mechanical stresses ${ }^{37}$ and the present study would be the first highlighting its relevance in SP. There are no previous studies relating keratin proteins with reproductive functions. The KRT17 is expressed in cervical mucosa and it is over-expressed in cervical carcinoma. ${ }^{38}$ With this background, it is difficult to elucidate how this SP-protein can influence the sperm fertilizing capacity and/or embryo development in the porcine species, but it could reflect the power of SP as a signal for the female, either initiating a transient inflammation or the long-lasting attainment of immune tolerance to paternal antigens by the female. ${ }^{39}$ Interestingly, keratin proteins also participate in regulating cell motility, ${ }^{40}$ maybe also sperm motility. The peptidyl-prolyl cis-trans isomerases (PPlases) are cellular enzymes widely distributed in the organism playing a relevant role as regulators of immune cell response. ${ }^{41}$ SMPDL3A is a protein carried by lysosomes, still poorly characterized and with putative anti-inflammatory and lipid-related roles. ${ }^{42}$ In the latter role, extracellular SMPDL3A would act hydrolyzing nucleotide substrates rather than membrane lipids, ${ }^{42}$ which in mammalian sperm would lead to capacitation. ${ }^{43}$ The BLMH is a cysteine aminopeptidase that protects cells against homocysteine, a metabolite whose excess is very toxic. ${ }^{44}$ In reproductive functionality, evidence 
suggests that homocysteine and related thiols are associated with male infertility, since the accumulation of homocysteine affects sperm functionality by inducing the generation of high intracellular reactive oxygen species (ROS) and subsequently the alteration of sperm proteins. ${ }^{45,46}$ The other four SP-proteins, Ubiquitin-like modifieractivating enzyme 1 (UBA1), Sperm adhesion molecule 1 (SPAM1), Furin and Aldose reductase (AKR1B1), showed a clear implication in male reproductive success. The UBA1 is responsible of ubiquitin activation leading to protein ubiquitination. Yi et al. ${ }^{47}$ described UBA1 in boar sperm acrosome and they suggested that it would play a pivotal role in sperm capacitation and zona pellucida (ZP) penetration. In boar, cytometric values of sperm ubiquitin were positively correlated with FR, but negatively with LS. ${ }^{48}$ Hyaluronidases are a family of proteins with well-known roles in mammalian sperm fertilization. ${ }^{49}$ The SPAM1, also known as $\mathrm{PH}-20$, is the main hyase protein described in the boar reproductive tract which, secreted by the seminal vesicle is present in SP. ${ }^{50}$ SPAM1 is essential for the fertilizing capacity of boar spermatozoa as it disperses the cumulus cell mass of oocyte and facilitates sperm-ZP binding. ${ }^{51}$ Furin is a calciumdependent serine endoprotease ubiquitously expressed in mammals, including the epididymal fluid of boars, where it would play an important role in sperm maturation, specifically promoting the acquisition of motility and fertilization capability. ${ }^{52}$ The enzyme AKR1B1 is essential for the synthesis of prostaglandin (PG) F2 $\alpha$ in the uterine endometrium. ${ }^{53}$ In pregnant sows, AKR1B1 would play a decisive role regulating the endometrial synthesis of PGF2 $\alpha$ during the first pregnancy stage facilitating the maintenance of pregnancy. ${ }^{54}$ The AKR1B1 may also play important roles in sperm functionality. Katoh et al. ${ }^{55}$ suggested that AKR1B1 would contribute to the acquisition of fertilizing capacity during the epididymal maturation of spermatozoa. Moreover, once in the female genital tract, AKR1B1 could play pivotal role in boar sperm 
capacitation mainly by regulating the sperm ability to generate ROS. ${ }^{55}$ The three underexpressed SP-proteins were Angiotensinogen (AGT), Keratin type I cytoskeletal 10 (KRT10) and Tetratricopeptide repeat protein 23 (TTC23). The first one, AGT, belongs to the serpin family and it is the substrate precursor of all bioactive angiotensin (AT) peptides implicated in the renin-angiotensin system that regulates blood pressure. ${ }^{56}$ In the male reproductive tract, AGT was identified in the rat epididymis ${ }^{57}$ and the resulting AT peptides in human SP, with a presumed involvement in male fertility ${ }^{58}$ although their specific roles remaining unclear. One of the resulting AT, specifically AT II, was found at high levels in azoospermic men. ${ }^{59}$ As mentioned above, the main function of keratin protein is to protect epithelial cells against mechanical stresses. ${ }^{37}$ Related to reproductive outcomes, a recent study found that serum concentration of KRT10 was particularly high at birth in intrauterine growth restricted infants. ${ }^{60}$ Tetratricopeptide repeat proteins (TPRs) are amino acid sequences involved in both protein-protein interaction and functionality of some chaperones, such as heat-shock proteins (Hsp), more specifically Hsp70 and Hsp90, that may influence on the action of reproductive hormones. ${ }^{61}$ It is not currently known whether TPRs are involved in male reproductive functions. However, some of them are over-expressed in canine prostate cancer $^{62}$ and involved in rat testis FSH receptor signaling. ${ }^{63}$

Focusing on LS, the LASSO approach identified 4 SP-proteins quantitatively expressed differently between boar exhibiting largest or smallest LS. Two of them were overexpressed (Desmocollin-1 and Catalase) and the other two under-expressed (Protease Nexin-1 and Trombospondin-1) in the boars showing the largest litter sizes. Desmocollin-1 (DSC1) is a cell surface serine protease expressed in male genital tract playing an essential role for tissue maintenance ${ }^{64}$ and it is involved in the spermatogenesis success. ${ }^{65}$ Catalase (CAT) is an enzyme present in SP of several 
species including porcine, ${ }^{66,67}$ showing well characterized functionality as ROSscavenger. Specifically, CAT decomposes hydrogen peroxide, the most dangerous ROS for boar spermatozoa, ${ }^{68}$ to water and oxygen, thereby protecting sperm against oxidative stress and consequently preventing the cells from suffering lipid peroxidation. Protease Nexin-1 (PN-1) is a serine protease inhibitor synthesized in the seminal vesicles that would contribute to regulate proteolytic activity of SP. The PN-1, like many other proteins found in SP, would have a bipolar effect. The lack of this protein would lead to infertility (verified in mice with deletion of the PN-1 gene) and secreted in excess to seminal vesicles dysfunctionality, as described in men. ${ }^{69}$ Trombospondin-1 (THBS1) is a potent anti-angiogenic protein ${ }^{70}$ that would alter the maternal-fetal interface during early pregnancy when it was present in the SP deposited during insemination in the female genital tract. ${ }^{71}$

In conclusion, a new pre-fractionation step combining the already used SEC and an approach based on SPE with a novel sorbent for protein isolation has been used for indepth proteomic SP-characterization in boars with differential fertility (FR) and prolificacy (LS). This is evidently the most extensive annotation of the boar SPproteome published to date. In addition, the quantification of identified SP-proteins with a SWATH approach among boars showing real fertility differences in terms of FR and LS, resulted in the identification of a panel of differentially expressed SP-proteins, some of them playing a pivotal role in reproductive processes. These results provide novel insight about the role of SP-proteins on boar fertility, acting as inducers of a series of processes at the sperm level, but also at the interaction with the female genital tract, including paradoxal immune responses to foreign proteins, which might eventually serve as biomarkers of fertility, at the earliest possible stage. Prediction of fertility and/or prolificacy using biomarkers in semen is a long-wish by academics and by the 
production and breeding industries. However, further validation of these proteins as biomarkers is necessary, probably with double-blind prospective testing for their suitability as boar fertility biomarkers.

\section{Supporting Information}

\section{The following files are available free of charge}

Table S1: Amount of protein $(\mu \mathrm{g})$ recovered at each step of the solid phase extraction (SPE) and for the each of the two pHs used.

Table S2: Fertility records of the 64 boars initially included in the study.

Table S3: Complete list of the 524 proteins identified in boar seminal plasma and validated with a peptide confidence threshold of $97 \%$ and a false discovery rate (FDR) $\leq$ 1\% by using size exclusion chromatography (SEC) as pre-fractionation step.

Table S4: Complete list of the 810 proteins identified in boar seminal plasma and validated with a peptide confidence threshold of $97 \%$ and a false discovery rate (FDR) $\leq$ 1\% by using solid phase extraction (SPE) as pre-fractionation step.

Table S5: Complete list of the 872 proteins identified in boar seminal plasma and validated with a peptide confidence threshold of $97 \%$ and a false discovery rate (FDR) $\leq$ $1 \%$ combining the libraries obtained by the two pre-fractionation procedures.

Table S6: Complete list of the 679 proteins quantitatively expressed in the boar seminal plasma.

Table S7: List of the quantification of 11 seminal plasma proteins differentially expressed between the 13 boars showing high- or low-farrowing rates. 
Table S8: List of the quantification of four seminal plasma proteins differentially expressed among the 13 boars showing large- and small- litter sizes.

\section{Author contributions}

J.R., H.R-M. and E.A.M. conceived the study, contributed to experimental design, revised the manuscript critically and provided fund for this research; C.P-P., I.P. and I.B. collected ejaculates, SP samples and fertility data, made the comprehensive analysis of the data derived from the proteomics analysis and also wrote the manuscript. M.V-B, J.M.H-M, E.F.S-A contributed to the proteomic analysis of the samples. All authors read and approved the final version of the manuscript.

\section{Conflict of Interest}

The authors declare no conflict of interest.

\section{Acknowledgements}

This experimental study was supported by MINECO and FEDER (AGL2015-69738-R and CTQ2014-52765-R) Madrid (Spain), Seneca Foundation (19892/GERM/15) Murcia

(Spain), PROMETEO/2016/145 (Generalitat Valenciana, Spain), The Swedish Research Council (VR, 521-2011-6353), the Swedish Research Council Formas (221-2011-512) and the Research Council in Southeast Sweden (FORSS, 378091/312971), Sweden. C. Perez-Patiño and M. Vergara-Barberan were financially supported by the Seneca Foundation (Murcia, Spain) and MINECO (Madrid, Spain), respectively. The authors are grateful to AIM Iberica (Topigs Norsvin Iberica) for supplying the boar ejaculates.

\section{References}


(1) Riesenbeck, A. Review on international trade with boar semen. Reprod Domest Anim. 2011, 46, 1-3.

(2) Roca, J.; Broekhuijse, M.L.; Parrilla, I.; Rodriguez-Martinez, H.; Martinez, E.A.; Bolarin A. Boar Differences In Artificial Insemination Outcomes: Can They Be Minimized? Reprod Domest Anim. 2015, 50, 48-55.

(3) Broekhuijse, M.L.; Gaustad, A.H.; Bolarin, A.; Knol, E.F. Efficient Boar Semen Production and Genetic Contribution: The Impact of Low-Dose Artificial Insemination on Fertility. Reprod Domest Anim. 2015, 50, 103-9.

(4) Roca, J.; Parrilla, I.; Bolarin, A.; Martinez, E.A.; Rodriguez-Martinez, H. Will AI in pigs become more efficient? Theriogenology. 2016, 86, 187-93.

(5) Mann, T.; Lutwak-Mann, C. Passage of chemicals into human and animal semen: mechanisms and significance. Crit Rev Toxicol. 1982, 11, 1-14.

(6) Dyck, M.K.; Foxcroft, G.R.; Novak, S.; Ruiz-Sanchez, A.; Patterson, J.; Dixon, W.T. Biological markers of boar fertility. Reprod Domest Anim. 2011, 46, 55-8.

(7) Bromfield, J.J. Seminal fluid and reproduction: much more than previously thought. $J$ Assist Reprod Genet. 2014, 31, 627-36.

(8) Novak, S.; Ruiz-Sánchez, A.; Dixon, W.T.; Foxcroft, G.R.; Dyck, M.K. Seminal plasma proteins as potential markers of relative fertility in boars. J Androl. 2010, 31, 188-200.

(9) Barranco, I.; Tvarijonaviciute, A.; Perez-Patiño, C.; Alkmin, D.V.; Ceron, J.J.; Martinez, E.A.; Rodriguez-Martinez, H.; Roca, J. The activity of paraoxonase type 1 (PON-1) in boar seminal plasma and its relationship with sperm quality, functionality, and in vivo fertility. Andrology. 2015, 3, 315-20.

(10) Barranco, I.; Tvarijonaviciute, A.; Perez-Patiño, C.; Vicente-Carrillo, A.; Parrilla, I.; Ceron, J.J.; Martinez, E.A.; Rodriguez-Martinez, H.; Roca, J. Glutathione Peroxidase 5 Is Expressed by the Entire Pig Male Genital Tract and Once in the Seminal Plasma Contributes to Sperm Survival and In Vivo Fertility. PLoS One. 2016, 11, e0162958.

(11) Flowers, W.L.; Deller, F.; Stewart, K.R. Use of heterospermic inseminations and paternity testing to evaluate the relative contributions of common sperm traits and seminal plasma proteins in boar fertility. Anim Reprod Sci. 2016, 174, 123-131.

(12) Druart, X.; Rickard, J.P.; Mactier, S.; Kohnke, P.L.; Kershaw-Young, C.M.; Bathgate, R.; Gibb, Z.; Crossett, B.; Tsikis, G.; Labas, V.; Harichaux, G.; Grupen, C.G.; de Graaf, S.P. Proteomic characterization and cross species comparison of mammalian seminal plasma. J Proteomics. 2013, 91, 13-22.

(13) González-Cadavid, V.; Martins, J.A.; Moreno, F.B.; Andrade, T.S.; Santos, A.C.; Monteiro-Moreira, A.C.; Moreira, R.A.; Moura, A.A. Seminal plasma proteins of adult boars and correlations with sperm parameters.Theriogenology. 2014, 82, 697-707. 
(14) Perez-Patiño, C.; Barranco, I.; Parrilla, I.; Valero, M.L.; Martinez, E.A.; RodriguezMartinez, H.; Roca, J. Characterization of the porcine seminal plasma proteome comparing ejaculate portions. J Proteomics. 2016, 142, 15-23.

(15) Pilch, B.; Mann, M. Large-scale and high-confidence proteomic analysis of human seminal plasma. Genome Biol. 2006, 7, R40.

(16) Batruch, I.; Lecker, I.; Kagedan, D.; Smith, C.R.; Mullen, B.J.; Grober, E.; Lo, K.C.; Diamandis, E.P.; Jarvi, K.A. Proteomic analysis of seminal plasma from normal volunteers and post-vasectomy patients identifies over 2000 proteins and candidate biomarkers of the urogenital system. J Proteome Res. 2011, 10, 941-53.

(17) Batruch, I.; Smith, C.R.; Mullen, B.J.; Grober, E.; Lo, K.C.; Diamandis, E.P.; Jarvi, K.A. Analysis of seminal plasma from patients with non-obstructive azoospermia and identification of candidate biomarkers of male infertility. J Proteome Res. 2012, 11, 1503-

11.

(18) Rolland, A.D.; Lavigne, R.; Dauly, C.; Calvel, P.; Kervarrec, C.; Freour, T.; Evrard, B.; Rioux-Leclercq, N.; Auger, J.; Pineau, C. Identification of genital tract markers in the human seminal plasma using an integrative genomics approach. Hum Reprod. 2013, 28, 199-209.

(19) Vergara-Barberán, M.; Lerma-García, M.J.; Simó-Alfonso, E.F.; Herrero-Martínez, J.M. Solid-phase extraction based on ground methacrylate monolith modified with gold nanoparticles for isolation of proteins. Anal Chim Acta. 2016, 917, 37-43.

(20) Vergara-Barberán, M.; Lerma-García, M.J.; Simó-Alfonso, E.F.; Herrero-Martínez, J.M. Polymeric sorbents modified with gold and silver nanoparticles for solid-phase extraction of proteins followed by MALDI-TOF analysis. Microchimica Acta. 2017, 184, 1683-1690

(21) Shevchenko, A.; Wilm, M.; Vorm, O.; Mann, M. Mass spectrometric sequencing of proteins silver-stained polyacrylamide gels. Anal Chem. 1996, 68, 850-8.

(22) Gillet, L.C.; Navarro, P.; Tate, S.; Röst, H.; Selevsek, N.; Reiter, L.; Bonner, R.; Aebersold, R. Targeted data extraction of the MS/MS spectra generated by dataindependent acquisition: a new concept for consistent and accurate proteome analysis. Mol Cell Proteomics. 2012, 11, O111.016717.

(23) Broekhuijse, M.L.; Soštarić, E.; Feitsma, H.; Gadella, B.M. The value of microscopic semen motility assessment at collection for a commercial artificial insemination center, a retrospective study on factors explaining variation in pig fertility. Theriogenology. 2012, 77, 1466-1479.

(24) Tibshirani, R. Regression shrinkage and selection via the lasso. J. R. Statist. Soc. 1996, 58, 267-288. 
(25) Anderson, N.L.; Anderson, N.G.; The human plasma proteome: history, character, and diagnostic prospects. Mol Cell Proteomics. 2002, 1, 845-67.

(26) Zhang, A.; YE, F.; Lu, J.; Wei, Z.; Peng, Y.; Zhao S. Preparation and Characterization of Polymer Solid Phase Microextraction Monolith Modified with Gold Nanoparticle. Chinese J Anal chem. 2011, 39, 1247-1250.

(27) Cao, Q.; Xu, Y.; Liu, F.; Svec, F.; Fréchet, J.M. Polymer monoliths with exchangeable chemistries: use of gold nanoparticles as intermediate ligands for capillary columns with varying surface functionalities. Anal Chem. 2010, 82, 7416-21.

(28) Xu, Y.; Cao, Q.; Svec, F.; Fréchet, J.M. Porous polymer monolithic column with surface-bound gold nanoparticles for the capture and separation of cysteine-containing peptides. Anal Chem. 2010, 82, 3352-8.

(29) Shilov, I.V.; Seymour, S.L.; Patel, A.A.; Loboda, A.; Tang, W.H.; Keating, S.P.; Hunter, C.L.; Nuwaysir, L.M.; Schaeffer, D.A. The Paragon Algorithm, a next generation search engine that uses sequence temperature values and feature probabilities to identify peptides from tandem mass spectra. Mol Cell Proteomics. 2007, 6, 1638-55.

(30) Shteynberg, D.; Nesvizhskii, A.I.; Moritz, R.L.; Deutsch, E.W. Combining results of multiple search engines in proteomics. Mol Cell Proteomics. 2013, 12, 2383-93.

(31) Calvete, J.J.; Sanz, L. Insights into structure-function correlations of ungulate seminal plasma proteins. Soc Reprod Fertil Suppl. 2007, 65, 201-15.

(32) Caballero, I.; Parrilla, I.; Almiñana, C.; del Olmo, D.; Roca, J.; Martínez, E.A.; Vázquez, J.M. Seminal plasma proteins as modulators of the sperm function and their application in sperm biotechnologies. Reprod Domest Anim. 2012, 47, 12-21.

(33) Rodríguez-Martínez, H.; Kvist, U.; Ernerudh, J.; Sanz, L.; Calvete, J.J. Seminal plasma proteins: what role do they play? Am J Reprod Immunol. 2011, 66, 11-22.

(34) Caballero, I.; Parrilla, I.; Almiñana, C.; del Olmo, D.; Roca, J.; Martínez, E.A.; Vázquez, J.M. Seminal plasma proteins as modulators of the sperm function and their application in sperm biotechnologies. Reprod Domest Anim. 2012, 47, 12-21.

(35) Töpfer-Petersen, E.; Romero, A.; Varela, P.F.; Ekhlasi-Hundrieser, M.; Dostàlovà, Z.; Sanz, L.; Calvete, J.J. Spermadhesins: a new protein family. Facts, hypotheses and perspectives. Andrologia. 1998, 30, 217-24.

(36) Li, Z.; Sillanpää, M.J. Overview of LASSO-related penalized regression methods for quantitative trait mapping and genomic selection. Theor Appl Genet. 2012, 125, 419-35.

(37) Gu, L.H.; Coulombe, P.A. Keratin function in skin epithelia: a broadening palette with surprising shades. Curr Opin Cell Biol. 2007, 19, 13-23.

(38) Escobar-Hoyos, L.F.; Yang, J.; Zhu, J.; Cavallo, J.A.; Zhai, H.; Burke, S.; Koller, A.; Chen, E.I.; Shroyer, K.R. Keratin 17 in premalignant and malignant squamous lesions of the 
cervix: proteomic discovery and immunohistochemical validation as a diagnostic and prognostic biomarker. Mod Pathol. 2014, 27, 621-30.

(39) Robertson, S.A. Seminal fluid signaling in the female reproductive tract: lessons from rodents and pigs. J Anim Sci. 2007, 85, 36-44.

(40) Chiang, C.H.; Wu, C.C.; Lee, L.Y.; Li, Y.C.; Liu, H.P.; Hsu, C.W.; Lu, Y.C.; Chang, J.T.; Cheng, A.J. Proteomics Analysis Reveals Involvement of Krt17 in Areca Nut-Induced Oral Carcinogenesis. J Proteome Res. 2016, 15, 2981-97.

(41) Nath, P.R.; Isakov, N. Insights into peptidyl-prolyl cis-trans isomerase structure and function in immunocytes. Immunol Lett. 2015, 163, 120-31.

(42) Gorelik, A.; Illes, K.; Superti-Furga, G.; Nagar, B. Structural Basis for Nucleotide Hydrolysis by the Acid Sphingomyelinase-like Phosphodiesterase SMPDL3A. J Biol Chem. 2016, 291, 6376-85.

(43) Cisneros-Mejorado, A.; Sánchez Herrera, D.P. cGMP and cyclic nucleotide-gated channels participate in mouse sperm capacitation. FEBS Lett. 2012, 586, 149-53.

(44) Zimny, J.; Sikora, M.; Guranowski, A.; Jakubowski, H. Protective mechanisms against homocysteine toxicity: the role of bleomycin hydrolase. J Biol Chem. 2006, 281, 22485-92.

(45) Ebisch, I.M.; Peters, W.H.; Thomas, C.M.; Wetzels, A.M.; Peer, P.G.; SteegersTheunissen, R.P. Homocysteine, glutathione and related thiols affect fertility parameters in the (sub)fertile couple. Hum Reprod. 2006, 21, 1725-33.

(46) Aitken, R.J.; Flanagan, H.M.; Connaughton, H.; Whiting, S.; Hedges, A.; Baker, M.A. Involvement of homocysteine, homocysteine thiolactone, and paraoxonase type 1 (PON-1) in the etiology of defective human sperm function. Andrology. 2016, 4, 345-60.

(47) Yi, Y.J.; Zimmerman, S.W.; Manandhar, G.; Odhiambo, J.F.; Kennedy, C.; Jonáková, V.; Maňásková-Postlerová, P.; Sutovsky, M.; Park, C.S.; Sutovsky, P. Ubiquitin-activating enzyme (UBA1) is required for sperm capacitation, acrosomal exocytosis and sperm-egg coat penetration during porcine fertilization. Int J Androl. 2012, 35, 196-210.

(48) Lovercamp, K.W.; Safranski, T.J.; Fischer, K.A.; Manandhar, G.; Sutovsky, M.; Herring, W.; Sutovsky, P. Arachidonate 15-lipoxygenase and ubiquitin as fertility markers in boars. Theriogenology. 2007, 67, 704-18.

(49) Martin-DeLeon, P.A. Epididymal SPAM1 and its impact on sperm function. Mol Cell Endocrinol. 2006, 250, 114-21.

(50) Cibulková, E.; Manásková, P.; Jonáková, V.; Tichá, M. Preliminary characterization of multiple hyaluronidase forms in boar reproductive tract. Theriogenology. 2007, 68, 104754.

(51) Yoon, S.; Chang, K.T.; Cho, H.; Moon, J.; Kim, J.S.; Min, S.H.; Koo, D.B.; Lee, S.R.; Kim, S.H.; Park, K.E.; Park, Y.I.; Kim, E. Characterization of pig sperm hyaluronidase and 
improvement of the digestibility of cumulus cell mass by recombinant pSPAM1 hyaluronidase in an in vitro fertilization assay. Anim Reprod Sci. 2014, 150, 107-14.

(52) Thimon, V.; Belghazi, M.; Dacheux, J.L.; Gatti, J.L. Analysis of furin ectodomain shedding in epididymal fluid of mammals: demonstration that shedding of furin occurs in vivo. Reproduction. 2006, 132, 899-908.

(53) Bresson, E.; Boucher-Kovalik, S.; Chapdelaine, P.; Madore, E.; Harvey, N.; Laberge, P.Y.; Leboeuf, M.; Fortier, M.A. The human aldose reductase AKR1B1 qualifies as the primary prostaglandin F synthase in the endometrium. J Clin Endocrinol Metab. 2011, 96, 210-9.

(54) Seo, H.; Choi, Y.; Shim, J.; Yoo, I.; Ka, H. Comprehensive analysis of prostaglandin metabolic enzyme expression during pregnancy and the characterization of AKR1B1 as a prostaglandin F synthase at the maternal-conceptus interface in pigs. Biol Reprod. 2014, 90,

99.

(55) Katoh, Y.; Takebayashi, K.; Kikuchi, A.; Iki, A.; Kikuchi, K.; Tamba, M.; Kawashima, A.; Matsuda, M.; Okamura, N. Porcine sperm capacitation involves tyrosine phosphorylation and activation of aldose reductase. Reproduction. 2014, 148, 389-401.

(56) Lu, H.; Cassis, L.A.; Kooi, C.W.; Daugherty, A. Structure and functions of angiotensinogen. Hypertens Res. 2016, 39, 492-500.

(57) Leung, P.S.; Wong, T.P.; Sernia, C. Angiotensinogen expression by rat epididymis: evidence for an intrinsic, angiotensin-generating system. Mol Cell Endocrinol. 1999, 155, 115-22.

(58) O'Mahony, O.A.; Barker, S.; Puddefoot, J.R.; Vinson, G.P. Synthesis and secretion of angiotensin II by the prostate gland in vitro. Endocrinology. 2005, 146, 392-8.

(59) Zheng, S.; Li, Z.; Wang, Y.X.; Xiang, Z.Q. Seminal plasma angiotensin II detection and its clinical implication. Zhonghua Nan Ke Xue. 2003, 9, 669-72.

(60) Ruis-González, M.D.; Cañete, M.D.; Gómez-Chaparro, J.L.; Abril, N.; Cañete, R.; López-Barea, J. Alterations of protein expression in serum of infants with intrauterine growth restriction and different gestational ages. J Proteomics. 2015, 119, 169-82.

(61) Roberts, J.D.; Thapaliya, A.; Martínez-Lumbreras, S.; Krysztofinska, E.M.; Isaacson, R.L. Structural and Functional Insights into Small, Glutamine-Rich, Tetratricopeptide Repeat Protein Alpha. Front Mol Biosci. 2015, 2, 71.

(62) Azakami, D.; Nakahira, R.; Kato, Y.; Michishita, M.; Kobayashi, M.; Onozawa, E.; Bonkobara, M.; Kobayashi, M.; Takahashi, K.; Watanabe, M.; Ishioka, K.; Sako, T.; Ochiai, K.; Omi, T. The canine prostate cancer cell line CHP-1 shows over-expression of the co-chaperone small glutamine-rich tetratricopeptide repeat-containing protein $\alpha$. Vet Comp Oncol. 2017, 15, 557-562. 
(63) Ohta, M.; Ohyama, K.; Asano, A.; Yokota, S.; Khalid, A.M.; Yamano, Y. Regulation of rat tetratricopeptide repeat domain 29 gene expression by follicle-stimulating hormone.

Biosci Biotechnol Biochem. 2012, 76, 1540-3.

(64) Hobson, J.P.; Netzel-Arnett, S.; Szabo, R.; Réhault, S.M.; Church, F.C.; Strickland, D.K.; Lawrence, D.A.; Antalis, T.M.; Bugge, T.H. Mouse DESC1 is located within a cluster of seven DESC1-like genes and encodes a type II transmembrane serine protease that forms serpin inhibitory complexes. J Biol Chem. 2004, 279, 46981-94.

(65) Mruk, D.D.; Xiao, X.; Lydka, M.; Li, M.W.; Bilinska, B.; Cheng, C.Y. Intercellular adhesion molecule 1: recent findings and new concepts involved in mammalian spermatogenesis. Semin Cell Dev Biol. 2014, 29, 43-54.

(66) Marti, E.; Mara, L.; Marti, J.I.; Muiño-Blanco, T.; Cebrián-Pérez, J.A. Seasonal variations in antioxidant enzyme activity in ram seminal plasma. Theriogenology. 2007, 67, 1446-54.

(67) Koziorowska-Gilun, M.; Koziorowski, M.; Fraser, L.; Strzeżek, J. Antioxidant defence system of boar cauda epididymidal spermatozoa and reproductive tract fluids. Reprod Domest Anim. 2011, 46, 527-33.

(68) Awda, B.J.; Mackenzie-Bell, M.; Buhr, M.M. Reactive oxygen species and boar sperm function. Biol Reprod. 2009, 81, 553-61.

(69) Murer, V.; Spetz, J.F.; Hengst, U.; Altrogge, L.M.; de Agostini, A.; Monard, D. Male fertility defects in mice lacking the serine protease inhibitor protease nexin-1. Proc Natl Acad Sci U S A. 2001, 98, 3029-33.

(70) Rusnati, M.; Urbinati, C.; Bonifacio, S.; Presta, M.; Taraboletti, G. Thrombospondin-1 as a Paradigm for the Development of Antiangiogenic Agents Endowed with Multiple Mechanisms of Action. Pharmaceuticals (Basel). 2010, 3, 1241-1278.

(71) Edwards, A.K.; van den Heuvel, M.J.; Wessels, J.M.; Lamarre, J.; Croy, B.A.; Tayade, C. Expression of angiogenic basic fibroblast growth factor, platelet derived growth factor, thrombospondin-1 and their receptors at the porcine maternal-fetal interface. Reprod Biol Endocrinol. 2011, 9, 5.

\section{Figure Captions}

Figure 1: Boar selection criteria according to fertility records of farrowing rate (FR) and litter size (LS). 
Figure 2: Bar chart showing the deviation in farrowing rate and litter size of selected boars. The 0 represent the average for each genetic line in terms of direct boar effect. (See Table 1).

Figure 3: Pie charts representing the distribution of the proteins identified in boar seminal plasma according to (a) molecular function; (b) biological process; (c) cellular component and those specifically involved in reproductive process (d) using UniProt KB database (www.uniprot.org)

Figure 4: Heatmap depicting the 11 boar seminal plasma proteins differentially expressed between sires with high- or low-farrowing rate after applying LASSO regression shrinkage parameter $\lambda_{2}$ (minimum value obtained for the model). Expression shown is mean centered. The red indicates increased and green down-regulated expression while black indicates mean value. FR_dev: farrowing rate deviation from average in terms of direct boar effect of each boar respecting to its genetic line.

Figure 5: Heatmap depicting the four boar seminal plasma proteins differentially expressed between sires yielding large- or small-litters after applying LASSO regression shrinkage parameter $\lambda_{1}$ (median value obtained after replicating 100 times the cross validation). Expression shown is mean centered. The red indicates increased and green down-regulated expression while black indicates mean value. LS_dev: litter size deviation from average in terms of direct boar effect of each boar respecting to its genetic line.

Figure 1 


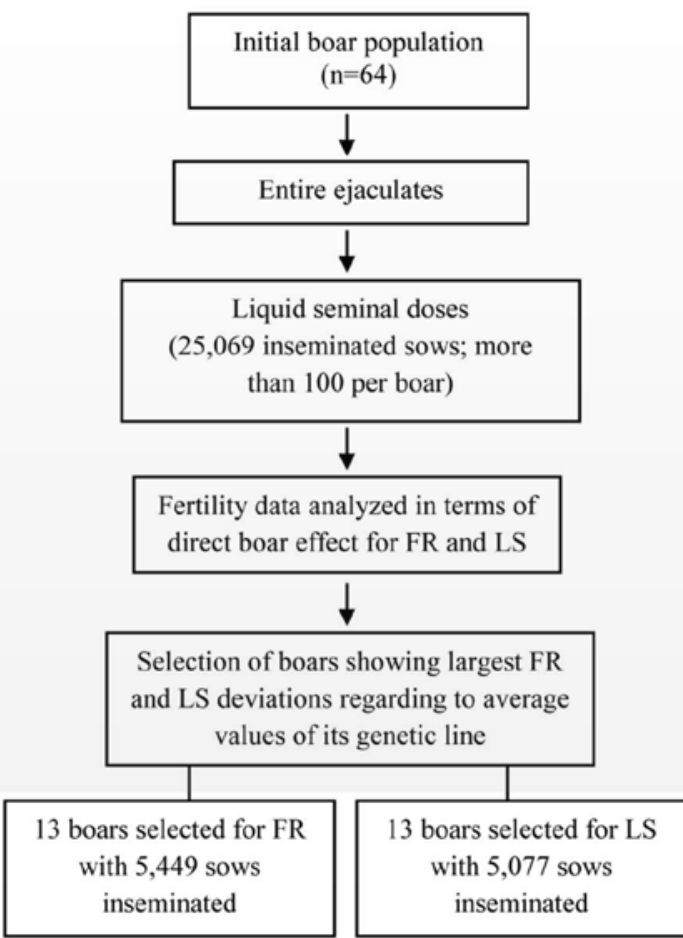

Figure 2

Farrowing Rate Deviation

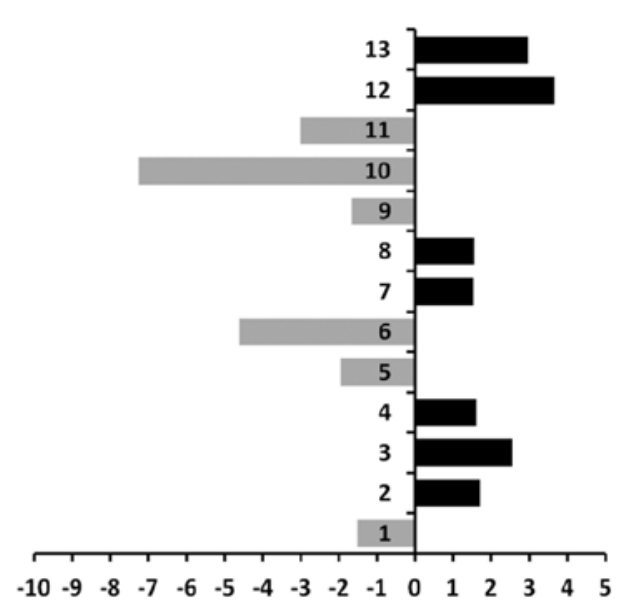

Litter Size Deviation

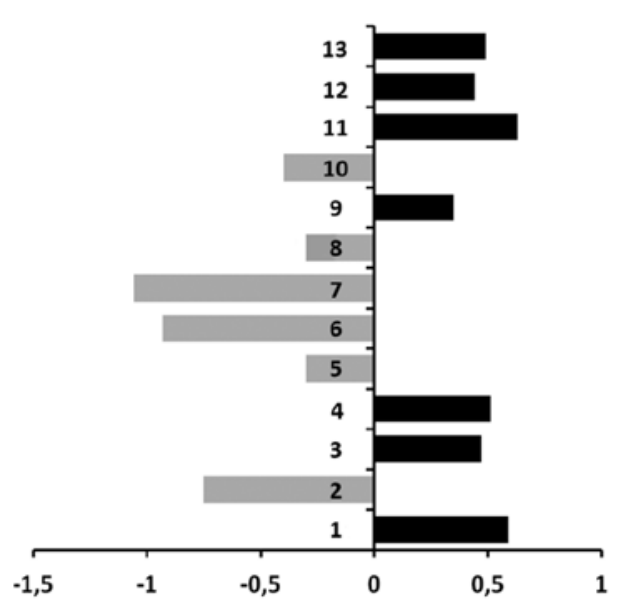

Figure 3 
A)

MOLECULAR FUNCTION

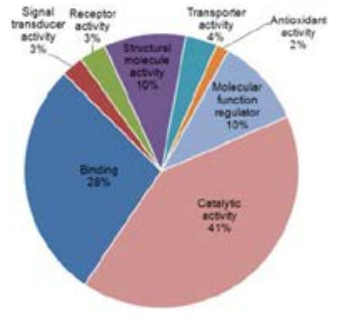

BIOLOGICAL PROCESS
CELLULAR COMPONENT

c)

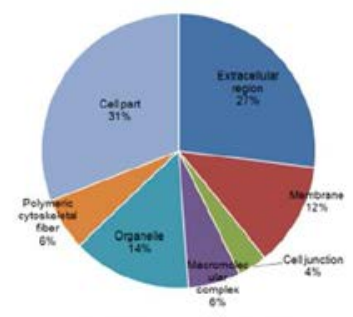

REPRODUCTIVE PROCESS

B)

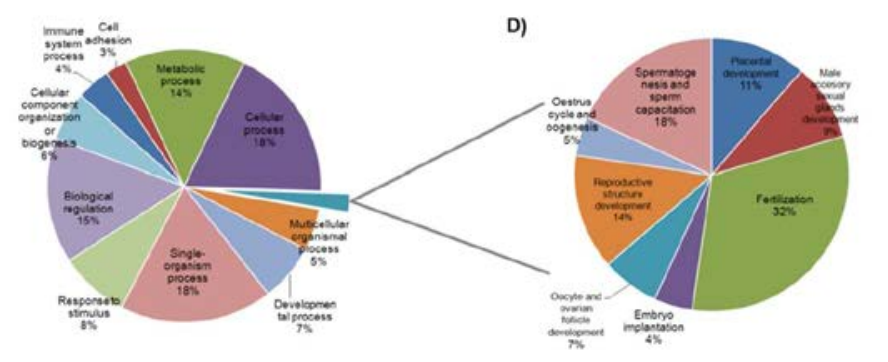


Figure 4

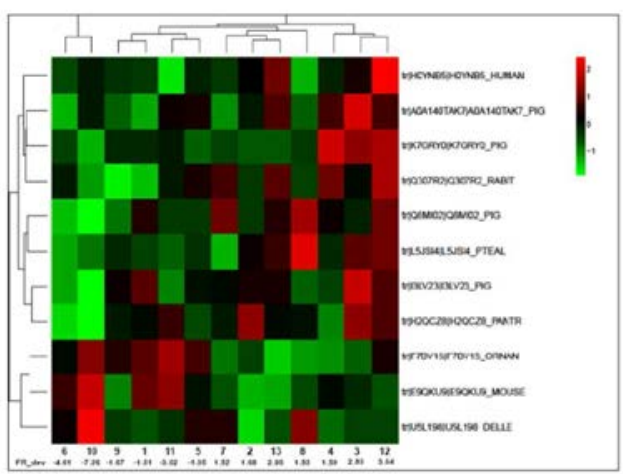

Figure 5

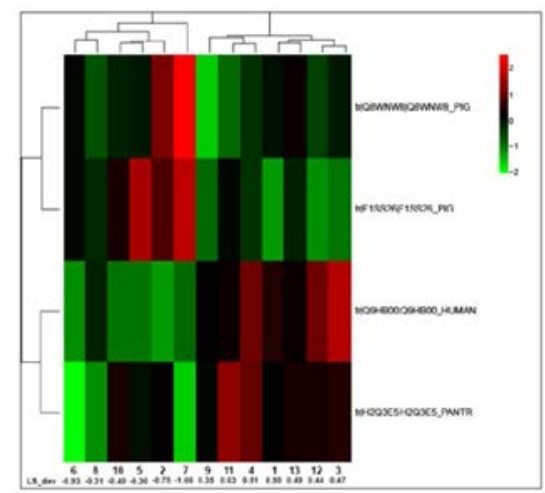

34

ACS Paragon Plus Environment 
Table 1. Fertility outcomes of 26 selected boars showing the largest deviations for farrowing rate $(F R, n=13)$ and litter size (LS, $n=13$ ), including the inseminated sows per boar and the mean for each genetic line. Fertility data are in terms of direct boar effect.

\begin{tabular}{|c|c|c|c|c|c|c|c|}
\hline \multicolumn{4}{|c|}{ Boars with larger deviations in Farrowing Rate } & \multicolumn{4}{|c|}{ Boars with larger deviations in Litter Size } \\
\hline \multirow{2}{*}{$\begin{array}{c}\text { Boar } \\
\text { number }\end{array}$} & \multirow{2}{*}{$\begin{array}{l}\text { Inseminated } \\
\text { sows (n) }\end{array}$} & \multicolumn{2}{|c|}{ FR (\%) } & \multirow{2}{*}{$\begin{array}{c}\text { Boar } \\
\text { number }\end{array}$} & \multirow{2}{*}{$\begin{array}{c}\text { Inseminated } \\
\text { sows (n) }\end{array}$} & \multicolumn{2}{|c|}{ LS (n) } \\
\hline & & Boar & $\begin{array}{c}\text { Genetic } \\
\text { Line }\end{array}$ & & & Boar & $\begin{array}{c}\text { Genetic } \\
\text { Line }\end{array}$ \\
\hline 1 & 397 & 85.59 & 87.10 & 1 & 273 & 13.79 & 13.20 \\
\hline 2 & 679 & 89.18 & 87.50 & 2 & 628 & 12.85 & 13.60 \\
\hline 3 & 605 & 90.63 & 88.10 & 3 & 516 & 13.97 & 13.50 \\
\hline 4 & 334 & 89.69 & 88.10 & 4 & 254 & 14.01 & 13.50 \\
\hline 5 & 211 & 85.55 & 87.50 & 5 & 135 & 13.30 & 13.60 \\
\hline 6 & 567 & 83.49 & 88.10 & 6 & 592 & 12.57 & 13.50 \\
\hline 7 & 215 & 89.62 & 88.10 & 7 & 187 & 12.44 & 13.50 \\
\hline 8 & 586 & 88.63 & 87.10 & 8 & 527 & 12.89 & 13.20 \\
\hline 9 & 556 & 86.43 & 88.10 & 9 & 213 & 13.85 & 13.50 \\
\hline 10 & 258 & 80.84 & 88.10 & 10 & 598 & 13.10 & 13.50 \\
\hline 11 & 174 & 84.48 & 87.50 & 11 & 415 & 14.23 & 13.60 \\
\hline 12 & 475 & 91.14 & 87.50 & 12 & 512 & 14.04 & 13.60 \\
\hline 13 & 392 & 91.05 & 88.10 & 13 & 227 & 13.99 & 13.50 \\
\hline
\end{tabular}


Table 2. List of quantitative differentially expressed seminal plasma proteins between boars showing high- and low-farrowing rate from Lasso regression using $\lambda_{2}$

\begin{tabular}{c|ccc}
\hline UniProtKB IDs & Protein Name & Gene Name & $\begin{array}{c}\text { Correlation } \\
\text { Coefficient }\end{array}$ \\
\hline H0YNB5_HUMAN & Furin & FURIN & 0.44 \\
\hline A0A140TAK7_PIG & Aldosereductase & AKR1B1 & 0.29 \\
\hline K7GRY0_PIG & Ubiquitin-like modifier-activating & UBA1 & 0.22 \\
\hline Q307R2_RABIT & Peptidyl-prolyl cis-trans isomerase & PIN1 & 0.18 \\
\hline Q8MI02_PIG & Sperm adhesion molecule 1 & SPAM1 & 0.70 \\
\hline L5JSI4_PTEAL & Bleomycinhydrolase & BLMH & 0.16 \\
\hline I3LV23_PIG & Sphingomyelin phosphodiesterase & SMPDL3A & 0.09 \\
\hline H2QCZ8_PANTR & Keratin type I cytoskeletal 17 & KRT17 & 1.21 \\
\hline F7BV15_ORNAN & Keratin type I cytoskeletal 10 & KRT10 & -0.33 \\
\hline E9QKU9_MOUSE & Tetratricopeptide repeat protein 23 & TTC23 & -0.95 \\
\hline U5L198_DELLE & Angiotensinogen & AGT & -0.43 \\
\hline$\lambda_{2}$ : the minimum value obtained for the model & & & \\
\hline
\end{tabular}

Table 3. List of quantitative differentially expressed seminal plasma proteins between boars showing large- and small-litter size from Lasso regression using $\lambda_{1}$

\begin{tabular}{c|cc|c}
\hline UniProtKB IDs & Protein Name & Gene Name & $\begin{array}{c}\text { Correlation } \\
\text { Coefficient }\end{array}$ \\
\hline Q8WNW8_PIG & Nexin-1 & PN-1 & -0.02 \\
\hline F1SS26_PIG & Trombospondin-1 & THBS1 & $-0.03 \times 10^{-3}$ \\
\hline Q9HB00_HUMAN & Desmocollin-1 & DSC1 & 0.30 \\
\hline H2Q3E5_PANTR & Catalase & CAT & 0.05 \\
\hline
\end{tabular}

$\lambda_{1}$ : the median value obtained after replicating 100 times the cross validation 


\section{For TOC only}

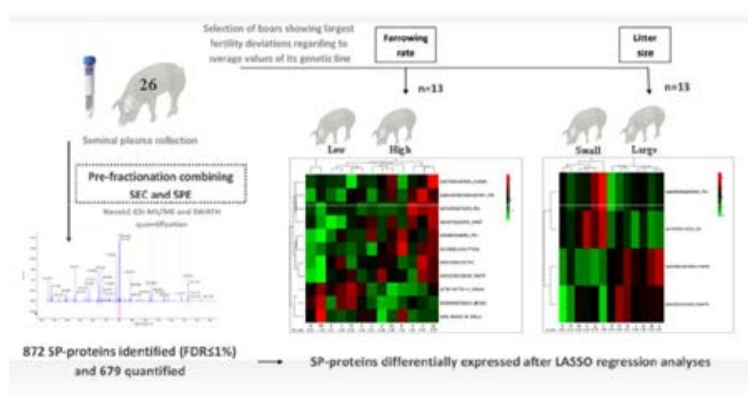

